\title{
The influence of marital status on the survival of patients with Hodgkin lymphoma
}

\author{
Fangfang Wang ${ }^{1, *}$, Xiaoyan Xie ${ }^{1, *}$, Xiaoming Yang ${ }^{2}$, Guoqing Jiang ${ }^{3}$ and Jian $\mathbf{G u}^{1}$ \\ ${ }^{1}$ Department of Hematology, Clinical Medical College of Yangzhou University, Subei People's Hospital of Jiangsu Province, \\ Yangzhou, China \\ ${ }^{2}$ Medical Department, Clinical Medical College of Yangzhou University, Subei People's Hospital of Jiangsu Province, Yangzhou, \\ China \\ ${ }^{3}$ Department of Hepatobiliary and Pancreatic Surgery, Clinical Medical College of Yangzhou University, Subei People's Hospital \\ of Jiangsu Province, Yangzhou, China \\ *These authors have contributed equally to this work \\ Correspondence to: Jian Gu, email: sbyyxyk@sina.com \\ Guoqing Jiang, email: jgqing2003@hotmail.com
}

Keywords: Hodgkin lymphoma, marital status, survival analysis, surveillance, epidemiology and end results

Received: February 08, $2017 \quad$ Accepted: March 21, $2017 \quad$ Published: April 06, 2017

Copyright: Wang et al. This is an open-access article distributed under the terms of the Creative Commons Attribution License 3.0 (CC BY 3.0), which permits unrestricted use, distribution, and reproduction in any medium, provided the original author and source are credited.

\section{ABSTRACT}

Marital status is viewed as an independent prognostic factor for survival in various cancers. But, little is known about the relationship between marital status and Hodgkin lymphoma (HL) outcomes. To investigate the impact of marital status on the survival of patients with HL,we identified 37884 cases from 1988 to 2013 in the Surveillance, Epidemiology and End Results (SEER) database. The Kaplan-Meier method and multivariate Cox regression model were used for analyzing the influence of marital status on cause-specific survival (CSS). We found patients in widowed group had a higher proportion of women and a higher incidence of older ( $>60$ years) patients; all of these parameters were found to be statistically significant in withingroup comparisons. Marital status was demonstrated to be an independent prognostic factor. Widowed individuals were at greater risk of cancer specific mortality relative to other groups. Similar associations in subgroup analyses were observed according to SEER stage. In conclusion, widowed patients suffered survival disadvantages relative to other groups, and marital status had significant prognostic value in $\mathrm{HL}$.

\section{INTRODUCTION}

Hodgkin lymphoma (HL) is a rare cancer of the lymphatic system [1]. It accounts for $10 \%$ of all lymphomas and less than $1 \%$ of all cancers diagnosed in United States (US) annually [2]. Approximately 8500 new patients $(3,710$ females and 4,790 males) will be diagnosed with HL and 1120 (480 females and 640 males) will die of the disease in the US in 2016 according to projections $[2,3]$. In the $1960 \mathrm{~s}$, the 5 -year survival rate for HL was less than 10\% [4]. Because of advances in treatment, survival has improved; the reported 5-year survival rate for patients with HL during the years 20002004 was $85.2 \%$ [5]. However, there are differences in patient survival related to the tumor's histology and its stage at diagnosis.

Marital status has been investigated a number of cancers with results often showing significant differences in incidence, disease characteristics and survival as a function of marital status [6]. A larger population-based study of data indicated that unmarried patients, including those who are widowed, are at significantly greater risk of presentation with metastatic cancer, undertreatment and cancer-related death than patients who are married [7]. Although numerous studies have measured the relationship between marital status and cancer incidence and survival, little is known about the relationship between marital status and HL outcomes. We used the Surveillance, Epidemiology and End Results (SEER) database to study the impact of marital 
status on HL cause-specific survival (CSS) and the survival disparities between married and unmarried individuals.

\section{RESULTS}

\section{Patient baseline characteristics}

A total of 37884 eligible patients were identified from 1988 to 2013, including 20633 male and 17251 female patients. Of these, 1610 were widowed, 16728 were married, 17034 had never married and 2512 were divorced /separated in our study. Patients in the widowed group had the following characteristics: the highest proportion of women; a greater prevalence of elderly patients (median 76 years). Both of these parameters differed significantly in within-group comparisons $(\mathrm{P}<0.001)$. The incidence rate of elderly patients ( $>60$ years) in widowed group was significantly higher than that of the younger widowed group ( $87.6 \%$ vs. $12.4 \%$ ), while the incidence rate among patients aged $>60$ years in married group, never married group and divorced/separated group was considerably lower than among younger patients. Patient demographics and pathological features are summarized in Table 1.

\section{Effect of marital status on CSS in the SEER database}

We performed Kaplan-Meier analysis to calculate CSS. The survival difference among the different marital status was significant according to the univariate log-rank test $(\mathrm{P}<0.001)$. The overall 5-year CSS was $37.4 \%$ in the widowed group, $80.9 \%$ in the married group, $87.9 \%$ in the never married group and $74.2 \%$ in the divorced/separated group; thus, widowed patients had a significantly inferior CSS as compared with the other groups (Figure 1A). In addition to marital status, male sex $(\mathrm{P}<0.001)$, Black ethnicity $(\mathrm{P}<0.001)$, old age $(\mathrm{P}<0.001)$, lymphocytedepleted (LD) histotype $(\mathrm{P}<0.001)$, Ann Arbor stage III/ IV $(\mathrm{P}<0.001)$ and early diagnosis $(\mathrm{P}<0.001)$ were found to be significant risk factors for poor survival in univariate analysis (Table 2). These variables were validated as independent prognostic factors when multivariate analysis with Cox regression was performed, as follows: sex; age; histotype; Ann Arbor stage; year of diagnosis; and marital status (widowed, 1.317, 95\% confidence interval [CI] 1.202-1.444; married, HR 0.711, 95\%CI 0.661-0.765; never married, HR $0.636,95 \%$ CI $0.587-0.688$ ).

\section{Subgroup analysis of the effects of marital status according to Ann Arbor stage}

We further explored the effects of marital status on survival regarding tumor stage. We observed that marital status was still an independent prognostic factor concerning tumor stage, both in univariate and multivariate analysis $(\mathrm{P}<0.001)$. In addition, patients in the widowed group always had the lowest survival rate. Widowed patients had a clear reduction in 5-year CSS as compared with the other groups with stage I/II ( $45.8 \%$ vs. $87.9 \%, 92.1 \%, 82.1 \%$; HR $3.834,95 \%$ CI $3.353-4.385, \mathrm{P}<0.001)$, stage III/IV $(29.6 \%$ vs. $69.1 \%, 81.6 \%, 64.5 \%$; HR $2.728,95 \%$ CI $2.411-3.086$, $\mathrm{P}<0.001)$ and stage Unknown $(30.6 \%$ vs. $78.2 \%, 84.4 \%$, 65.6\%; HR 3.160, 95\%CI 2.188-4.564, $\mathrm{P}<0.001$ ) cancer (Table 3, Figure 1B-1D). Moreover, the 5-year CSS in the never married group was the highest, with an increase of 2-3 times relative to the widowed groups (Table 3).

\section{DISCUSSION}

Our study is the largest to examine survival disparities as a function of marital status in HL population. Using the SEER database to investigate the relationship between marital status and survival, we found that marital status was an independent prognostic factor for patients with various Ann Arbor disease stages. Widowed patients had a significantly poorer CSS than married counterparts. In multivariate analysis, the risk for widowed patients persisted even after adjusting for sex, age, race, histotype, year of diagnosis and SEER stage. In addition, interaction was found between sex, age, year of diagnosis and marital status for these prognostic factors. The patients who were older $(>60$ years), more tumors at stage III/IV, early year of diagnosis or the inferior LD histotype, had the worst 5-year CSS.

It has been reported that unmarried individuals, especially widowed patients, have a lower CSS than married ones $[8,9]$. This also appears to be the case in our study, because marital status emerged as a statistically significant factor in both univariate analyses and in multivariate models. Regarding the widowed populations, a trend regarding increased mortality was less clear than in married populations. One of the potential reasons for the lower CSS in widowed patients is delayed diagnosis of patients with advanced tumor stages. In our study group, survival of patients with stage III/ IV in widowed group decreased sharply in the first 2 years (Figure 1C); they had a worse 5-year CSS as compared with all the other groups $(\mathrm{P}<0.001)$.

The relationship between marital status and survival can be explained hypothetically by psychosocial factors. A cancer diagnosis can be more psychologically distressing than other diagnoses [10]. Stress has been shown to have a more direct effect on physical health $[11,12]$. Psychological stress could in turn lead to more risky health-related behavior and poor sleep, thus adversely affecting general physical health status [13]. And some studies even suggest adverse effects regarding tumor growth [14]. It has been proposed that decreased psychosocial support and psychological stress alter immune function and contribute to tumor progression and mortality $[15,16]$. Patients who are married display less distress and anxiety than their unmarried counterparts after a diagnosis of cancer; this is because a partner can share the emotional burden and provide appropriate social 
Table 1: Baseline demographic and tumor characteristics of patients in the SEER database

\begin{tabular}{|c|c|c|c|c|c|c|}
\hline \multirow[t]{2}{*}{ Characteristic } & Total & Widowed & Married & Never married & $\begin{array}{l}\text { Divorced/ } \\
\text { separated }\end{array}$ & \multirow[t]{2}{*}{$\mathbf{P}$} \\
\hline & $(n=37884)$ & $\begin{array}{c}(\mathrm{n}=1610) \\
N(\%)\end{array}$ & $\begin{array}{c}(n=16728) \\
N(\%)\end{array}$ & $\begin{array}{c}(n=17034) \\
N(\%)\end{array}$ & $\begin{array}{c}(n=2512) \\
N(\%)\end{array}$ & \\
\hline Sex & & & & & & $<0.001$ \\
\hline Male & 20633 & $381(23.7)$ & $9420(56.3)$ & $9588(56.3)$ & $1224(49.5)$ & \\
\hline Female & 17251 & $1229(76.3)$ & $7308(43.7)$ & $7446(43.7)$ & $1268(50.5)$ & \\
\hline Race & & & & & & $<0.001$ \\
\hline White & 31554 & $1401(87.0)$ & $14633(87.5)$ & $13442(78.9)$ & $2078(82.7)$ & \\
\hline Black & 4296 & $138(8.6)$ & $1199(7.2)$ & $2610(15.3)$ & 349(13.9) & \\
\hline Other* & 2034 & $71(4.4)$ & $896(5.4)$ & $982(5.8)$ & $85(3.4)$ & \\
\hline $\operatorname{Age}^{\#}$ & & 76 & 43 & 24 & 48 & $<0.001$ \\
\hline$\leq 60$ & 31554 & $200(12.4)$ & $12945(77.4)$ & $16465(96.7)$ & 1944(77.4) & \\
\hline$>60$ & 6330 & $1410(87.6)$ & $3783(22.6)$ & $569(3.3)$ & $568(22.6)$ & \\
\hline Histotype & & & & & & $<0.001$ \\
\hline LR & 1218 & $64(4.0)$ & $648(3.9)$ & $403(2.4)$ & $103(4.1)$ & \\
\hline $\mathrm{MC}$ & 5189 & $371(23.0)$ & 2496(14.9) & 1891(11.1) & $431(17.2)$ & \\
\hline LD & 501 & $55(3.4)$ & $239(1.4)$ & $165(1.0)$ & $42(1.7)$ & \\
\hline NS & 22807 & $604(37.5)$ & $9600(57.4)$ & $11279(66.2)$ & $1324(52.7)$ & \\
\hline LP & 1590 & $52(3.2)$ & $774(4.6)$ & $652(3.8)$ & $112(4.5)$ & \\
\hline Unknown & 6579 & $464(28.8)$ & 2971(17.8) & $2644(15.5)$ & $500(19.9)$ & \\
\hline Ann Arbor stage & & & & & & $<0.001$ \\
\hline $\mathrm{I} / \mathrm{II}$ & 22179 & $763(47.4)$ & $10032(60.0)$ & $10016(58.8)$ & $1368(54.5)$ & \\
\hline III/IV & 14082 & $736(45.7)$ & $5948(35.6)$ & $6360(37.3)$ & $1038(41.3)$ & \\
\hline Unknown & 1622 & $111(6.9)$ & $748(4.5)$ & $657(3.9)$ & $106(4.2)$ & \\
\hline Year of diagnosis & & & & & & $<0.001$ \\
\hline 1988-1996 & 7234 & $327(20.3)$ & $3333(19.9)$ & $3112(18.3)$ & $462(18.4)$ & \\
\hline 1997-2005 & 14575 & $660(41.0)$ & $6608(39.5)$ & $6265(36.8)$ & $1042(41.5)$ & \\
\hline 2006-2013 & 16075 & $623(38.7)$ & $6787(40.6)$ & $7657(45)$ & $1008(40.1)$ & \\
\hline
\end{tabular}

*Other includes American Indian/Alaska native, Asian/Pacific Islander, and unknown.

\#-Median age.

support [17]. A study of the association between partner support and psychological distress among prostate cancer survivors showed that married prostate cancer survivors with high partner support reported significantly lower levels of psychological distress than unmarried survivors and married survivors with low partner support [18]. Additionally, psychological stress may cause poorer adherence to treatment regimens [13]. It is possible that married individuals receive better treatment from hospitals than unmarried individuals. A meta-analysis suggests that marriage positively influences adherence to treatment, partly through the partner's support [19]. Otherwise, unmarried patients may have more emotional burden and experience a lack of support from society and the spouse. Increased psychological stress may worsen cancer outcome $[18,20]$.

Interestingly, our study revealed that the 5-year CSS in the never-married group was better than in the married group, although survival benefits associated with married patients are supported by many studies. This may be the result of the following factors: good physical health because these patients are usually young at the 
time of diagnosis; the advantage of early disease stage; the protective effect of parental care; or extensive social support.

In the present study, the proportion of widowed elderly patients ( $>60$ years) was extremely high $(87.6 \%)$; this suggested that the inferior CSS of widowed patients may be correlated with age. The poor survival of elderly widowed women who might have poorer overall physical health at time of diagnosis may be driven by poorer socioeconomic status, decreased access to healthcare and loss of social support. The elderly widowed female patient's loss of social support or their inability to cope with stress may lead to increased mortality [21].

This study has several obvious strengths. The database is an authoritative source of information on cancer incidence and survival in the US, the timespan covered was rather large, and the patient and tumor information collected was very comprehensive. However, the present study had several limitations. We hypothesized that psychosocial factors may be the main reasons for poor survival of widowed patients; however, the patient's psychological condition at time of diagnosis was not known. Perhaps there were undiagnosed cases of mental disease in our sample. We were unable to adjust for pre-widowhood disease status, which had some impact on the CSS. Moreover, it has not been possible to distinguish between never-married and individuals who cohabit. Some patients who were classified as never married may have been cohabitating. In addition, some patient's marital status may have changed during the therapeutic process, which would have interfered with analytical results.

In conclusion, to the best of our knowledge this is the first study that has reported on the association between martial status and survival in patients with HL. Our study suggests that there was a strong positive relationship between these two factors; widowed patients had a significantly higher risk of mortality. Psychosocial factors may be one of the primary reasons for poor survival in widowed patients. More social support and care should be provided for these patients. Incorporating information about marital status into the design of intervention programs may help better target potential beneficiaries among widowed patients with HL.
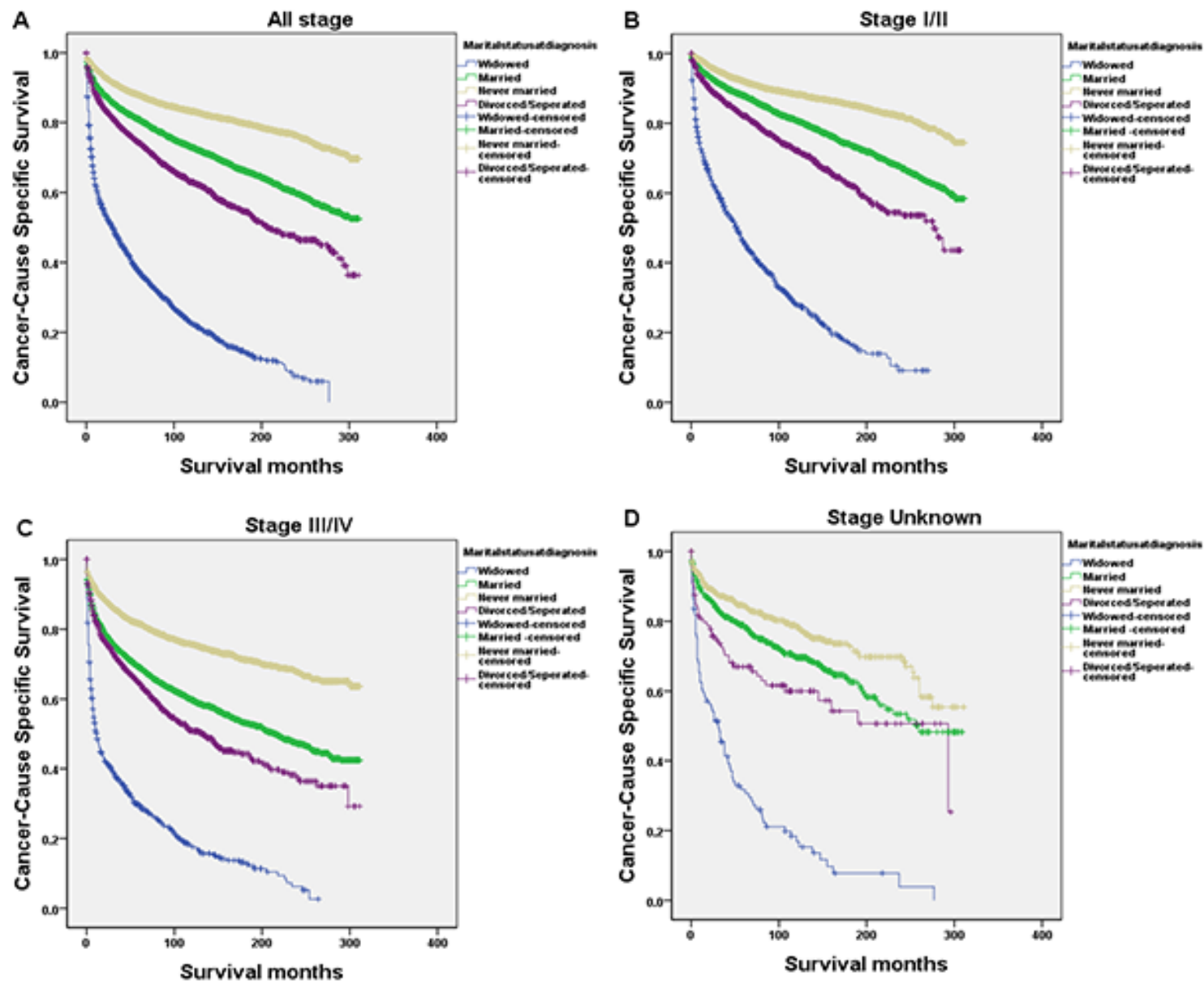

Figure 1: Survival curves in HL patients according to marital status. (A) Overall (Stage I-IV and Unknown); $\chi 2=4553.501$, $\mathrm{P}<0.0001$; (B) Stage I/II; $\chi 2=2630.949, \mathrm{P}<0.0001$; (C) Stage III/IV; $\chi 2=1632.126, \mathrm{P}<0.0001$; (D) Stage Unknown; $\chi 2=251.090 ; \mathrm{P}<0.0001$. 
Table 2: Univariate and multivariate survival analysis regarding evaluation of the influence of marital status on HL cause-specific survival in the SEER database

\begin{tabular}{|c|c|c|c|c|c|}
\hline \multirow[t]{2}{*}{ Variable } & \multirow[t]{2}{*}{ 5-year CCS } & \multicolumn{2}{|c|}{ Univariate analysis } & \multicolumn{2}{|c|}{ Multivariate analysis } \\
\hline & & $\underset{\text { test }}{\log \operatorname{rank}} \chi^{2}$ & $\mathbf{P}$ & HR(95\%CI) & $\mathbf{P}$ \\
\hline Sex & & 168.758 & $<0.001$ & & \\
\hline Male & $79.9 \%$ & & & $1.430(1.369-1.495)$ & $<0.001$ \\
\hline Female & $83.8 \%$ & & & Reference & \\
\hline Race & & 36.623 & $<0.001$ & & \\
\hline White & $81.9 \%$ & & & $1.004(0.907-1.111)$ & 0.942 \\
\hline Black & $79.1 \%$ & & & $1.440(1.282-1.616)$ & $<0.001$ \\
\hline Other* & $83.9 \%$ & & & Reference & \\
\hline Age & & 11542.410 & $<0.001$ & & \\
\hline$\leq 60$ & $88.9 \%$ & & & Reference & \\
\hline$>60$ & $45.4 \%$ & & & $5.479(5.202-5.770)$ & $<0.001$ \\
\hline Histotype & & 2218.610 & $<0.001$ & & \\
\hline LR & $84.8 \%$ & & & Reference & \\
\hline $\mathrm{MC}$ & $73.3 \%$ & & & $1.446(1.280-1.633)$ & $<0.001$ \\
\hline LD & $48.7 \%$ & & & $2.836(2.415-3.331)$ & $<0.001$ \\
\hline NS & $86.7 \%$ & & & $0.686(0.610-0.771)$ & $<0.001$ \\
\hline LP & $91.4 \%$ & & & $0.616(0.516-0.734)$ & $<0.001$ \\
\hline Unknown & $70.3 \%$ & & & $1.549(1.372-1.749)$ & $<0.001$ \\
\hline Ann Arbor stage & & 1445.803 & $<0.001$ & & \\
\hline $\mathrm{I} / \mathrm{II}$ & $87.9 \%$ & & & Reference & \\
\hline III/IV & $72.3 \%$ & & & $2.003(1.919-2.092)$ & $<0.001$ \\
\hline Unknown & $76.6 \%$ & & & $1.579(1.437-1.735)$ & $<0.001$ \\
\hline Year of diagnosis & & 75.552 & $<0.001$ & & \\
\hline 1988-1996 & $78.8 \%$ & & & $1.445(1.359-1.536)$ & $<0.001$ \\
\hline $1997-2005$ & $81.6 \%$ & & & $1.138(1.120-1.249)$ & $<0.001$ \\
\hline 2006-2013 & $83.7 \%$ & & & Reference & \\
\hline Marital status & & 4553.501 & $<0.001$ & & \\
\hline Widowed & $37.4 \%$ & & & $1.317(1.202-1.444)$ & $<0.001$ \\
\hline Married & $80.9 \%$ & & & $0.711(0.661-0.765)$ & $<0.001$ \\
\hline Never married & $87.9 \%$ & & & $0.635(0.587-0.688)$ & $<0.001$ \\
\hline Divorced/separated & $74.2 \%$ & & & Reference & \\
\hline
\end{tabular}

*Other includes American Indian/Alaska native, Asian/Pacific Islander, and unknown. 
Table 3: Univariate and multivariate analysis of the effects of marital status on HL cause-specific survival based on different cancer stages

\begin{tabular}{|c|c|c|c|c|c|}
\hline \multirow[t]{2}{*}{ Variable } & \multirow[t]{2}{*}{ 5-year CCS } & \multicolumn{2}{|c|}{ Univariate analysis } & \multicolumn{2}{|c|}{ Multivariate analysis } \\
\hline & & $\underset{\text { test }}{\log \operatorname{rank} \chi^{2}}$ & $\mathbf{P}$ & HR(95\%CI) & $\mathbf{P}$ \\
\hline \multicolumn{6}{|l|}{ Ann Arbor stage } \\
\hline \multicolumn{6}{|l|}{ Stage I/II } \\
\hline Marital status & & 2630.949 & $<0.001$ & & \\
\hline Widowed & $45.8 \%$ & & & $3.834(3.353-4.385)$ & $<0.001$ \\
\hline Married & $87.9 \%$ & & & $0.654(0.585-0.730)$ & $<0.001$ \\
\hline Never married & $92.1 \%$ & & & $0.365(0.324-0.410)$ & $<0.001$ \\
\hline Divorced/separated & $82.1 \%$ & & & Reference & \\
\hline \multicolumn{6}{|l|}{ Stage III/IV } \\
\hline Marital status & & 1632.126 & $<0.001$ & & \\
\hline Widowed & $29.6 \%$ & & & $2.728(2.411-3.086)$ & $<0.001$ \\
\hline Married & $69.1 \%$ & & & $0.804(0.727-0.889)$ & $<0.001$ \\
\hline Never married & $81.6 \%$ & & & $0.434(0.391-0.483)$ & $<0.001$ \\
\hline Divorced/separated & $64.5 \%$ & & & Reference & \\
\hline \multicolumn{6}{|l|}{ Unknown } \\
\hline Marital status & & 251.090 & $<0.001$ & & \\
\hline Widowed & $30.6 \%$ & & & $3.160(2.188-4.564)$ & $<0.001$ \\
\hline Married & $78.2 \%$ & & & $0.701(0.504-0.976)$ & 0.035 \\
\hline Never married & $84.4 \%$ & & & $0.495(0.351-0.698)$ & $<0.001$ \\
\hline Divorced/separated & $65.6 \%$ & & & Reference & \\
\hline
\end{tabular}

\section{MATERIALS AND METHODS}

\section{Data source}

Patient demographics, disease characteristics, survival data and marital status were obtained using the SEER program, which is sponsored by the National Cancer Institute [7]. The current SEER database consists of 18 population-based cancer registries acquired from 1988 to 2013 , which represent approximately $28 \%$ of the US population [22]. It is made available for researchers to study the relationship between marital status and the survival outcomes of patients with cancer [6-8, 23-26].

We limited the histological type of HL using the International Classification of Diseases for Oncology third edition (ICD-O-3) morphology codes (LR: 9651; MC: 9652; LD: 9653, 9654, 9655; LP: 9659; NS: 9663, 9664, 9665, 9667; and Unknown: 9650).

\section{Patient selection and data extracted}

Using the SEER-stat software (SEER*Stat 8.1.5), we searched for patients diagnosed between 1988 and 2013 with HL and a known marital status. Patient exclusion criteria were as follows: (1) they had more than one primary cancer but HL was not the first one; (2) they had unknown marital status; and (3) the cause of death was unknown or their survival time was unknown. We obtained data on patient gender, age, race, histotype, Ann Arbor stage, year of diagnosis and marital status from the SEER database.

\section{Statistical analysis}

Within the SEER database, the stage was established according to the $1983^{+}$Ann Arbor classification criteria. Marital status was coded as married, never married, widowed, divorced and separated. We assigned the separated and divorced patients into the divorced/ separated group in the present study [27].

Chi-squared tests were conducted to examine differences in the frequency of patient baseline characteristics among marital status. Differences in survival were estimated using the Kaplan-Meier method. We assessed differences in CSS by gender, age, race, histotype, Ann Arbor stage, year of diagnosis and marital status using the log-rank test or the multivariate Cox regression model. All of the statistical analyses were 
performed using the statistical software package SPSS for Windows, version 22 (IBM Corp, Armonk, NJ, USA). Statistical significance was set at a two-sided $P$ value $<0.05$.

\section{Abbreviations}

HL, Hodgkin lymphoma; SEER, Surveillance, Epidemiology and End Results; CSS, cause-specific survival; US, United States; HR, hazard ratio; CI, confidence interval; NS, nodular sclerosis; LD, lymphocyte-depleted; LR, lymphocyte-rich; MC, mixed cellularity; LP, lymphocyte-predominant; ICD-O-3, International Classification of Diseases for Oncology third edition.

\section{Author contributions}

JG and GQJ conceived of and designed the study. $\mathrm{XMY}$ contributed to analysis the data. FFW and XYX contributed to writing and editing the manuscript. All authors reviewed the manuscript.

\section{ACKNOWLEDGMENTS}

This study used the Surveillance, Epidemiology and End Results (SEER) database. The authors acknowledge the efforts of the SEER Program tumor registries in the creation of the SEER database. The interpretation and reporting of these data were the sole responsibility of the authors.

\section{CONFLICTS OF INTEREST}

The authors report no conflicts of interest.

\section{REFERENCES}

1. Sabattini E, Bacci F, Sagramoso C, Pileri SA. WHO classification of tumors of hematopoietic and lymphoid tissues in 2008: an overview. Pathologica. 2010; 102: 83-87.

2. Siegel RL, Miller KD, Jemal A. Cancer statistics, 2016. CA Cancer J Clin. 2016; 66: 7-30.

3. Surveillance, Epidemiology, and End Results Program. SEER Stat Fact Sheets: Hodgkin Lymphoma. National Cancer Institute. [Cited 2016 Oct 25]; Available from: http://seer.cancer.gov/statfacts/html/hodg.html.

4. Shenoy P, Maggioncalda A, Malik N, Flowers CR. Incidence patterns and outcomes for Hodgkin lymphoma patients in the United States. Adv Hematol. 2011; 2011: 725219 .

5. Brenner H, Gondos A, Pulte D. Ongoing improvement in long-term survival of patients with Hodgkin disease at all ages and recent catch-up of older patients. Blood. 2008; 111: 2977-2983.
6. Kravdal H, Syse A. Changes over time in the effect of marital status on cancer survival. BMC Public Health. 2011; 11: 804.

7. Aizer AA, Chen MH, McCarthy EP, Mendu ML, Koo S, Wilhite TJ, Graham PL, Choueiri TK, Hoffman KE, Martin $\mathrm{NE}, \mathrm{Hu}$ JC, Nguyen PL. Marital status and survival in patients with cancer. J Clin Oncol. 2013; 31: 3869-3876.

8. Kravdal O. The impact of marital status on cancer survival. Soc Sci Med. 2001; 52: 357-368.

9. He XK, Lin ZH, Qian Y, Xia D, Jin P, Sun LM. Marital status and survival in patients with primary liver cancer. Oncotarget. 2016 Aug 5. doi: 10.18632/oncotarget.11066. [Epub ahead of print].

10. Kaiser NC, Hartoonian N, Owen JE. Toward a cancer specific model of psychological distress: population data from the 2003-2005 National Health Interview Surveys. J Cancer Surviv. 2010; 4: 291-302.

11. Molloy GJ, Stamatakis E, Randall G, Hamer M. Marital status, gender and cardiovascular mortality: behavioral, psychological distress and metabolic explanations. Soc Sci Med. 2009; 69: 223-228.

12. Thoits PA. Stress and health: major findings and policy implications. J Health Soc Behav. 2010; 51: S41-S53.

13. Cohen S, Janicki-Deverts D, Miller GE. Psychological stress and disease. JAMA. 2007; 298: 1685-1687.

14. Chida Y, Hamer M, Wardle J, Steptoe A. Do stress-related psychosocial factors contribute to cancer incidence and survival? Nat Clin Pract Oncol. 2008; 5: 466-475.

15. Moreno-Smith M, Lutgendorf SK, Sood AK. Impact of stress on cancer metastasis. Future Oncol. 2010; 6: 1863-1881.

16. Jaremka LM, Glaser R, Malarkey WB, Kiecolt-Glaser JK. Marital distress prospectively predicts poorer cellular immune function. Psychoneuroendocrinology. 2013; 38: 2713-2719.

17. Goldzweig G, Andritsch E, Hubert A, Brenner B, Walach N, Perry S, Baider L. Psychological distress among male patients and male spouses: what do oncologists need to know? Ann Oncol. 2010; 21: 877-883.

18. Kamen C, Mustian KM, Heckler C, Janelsins MC, Peppone LJ, Mohile S, McMahon JM, Lord R, Flynn PJ, Weiss M, Spiegel D, Morrow GR. The association between partner support and psychological distress among prostate cancer survivors in a nationwide study. J Cancer Surviv. 2015; 9: 492-499.

19. DiMatteo MR. Social support and patient adherence to medical treatment: a meta-analysis. Health Psychol. 2004; 23: 207-218.

20. Croft L, Sorkin J, Gallicchio L. Marital status and optimism score among breast cancer survivors. Support Care Cancer. 2014; 22: 3027-3034.

21. Perkins JM, Lee HY, James KS, Krishna A, Heo J, Lee JK, Subramanian SV. Marital status, widowhood duration, 
gender and health outcomes: a cross-sectional study among older adults in India. BMC Public Health. 2016; 16: 1032.

22. Inverso G, Mahal BA, Aizer AA, Donoff RB, Chau NG, Haddad RI. Marital status and head and neck cancer outcomes. Cancer. 2015; 121: 1273-1278.

23. Nelles JL, Joseph SA, Konety BR. The impact of marriage on bladder cancer mortality. Urol Oncol. 2009; 27: 263-267.

24. Wang L, Wilson SE, Stewart DB, Hollenbeak CS. Marital status and colon cancer outcomes in US Surveillance, Epidemiology and End Results registries: does marriage affect cancer survival by gender and stage? Cancer Epidemiol. 2011; 35: 417-422.
25. Denberg TD, Beaty BL, Kim FJ, Steiner JF. Marriage and ethnicity predict treatment in localized prostate carcinoma. Cancer. 2005; 103: 1819-1825.

26. Rippentrop JM, Joslyn SA, Konety BR. Squamous cell carcinoma of the penis: evaluation of data from the surveillance, epidemiology, and end results program. Cancer. 2004; 101: 1357-1363.

27. Li Q, Gan L, Liang L, Li X, Cai S. The influence of marital status on stage at diagnosis and survival of patients with colorectal cancer. Oncotarget. 2015; 6: 7339-7347. doi: 10.18632/oncotarget.3129. 